\title{
Determination of testosterone esters in the hair of male greyhound dogs using liquid chromatography high resolution mass spectrometry
}

Jayasree Leela Devi ${ }^{a}$, Paul Zahra ${ }^{b}$, John H. Vine ${ }^{b}$, Ted Whittem ${ }^{a}$

${ }^{a}$ Translational Research and Animal Clinical Trial Study Group, Melbourne Veterinary School, Faculty of Veterinary and Agricultural Sciences, The University of Melbourne, 250 Princess Highway, Werribee, Victoria 3030, Australia

${ }^{b}$ Racing Analytical Services Limited, 400 Epsom Road, Flemington, Victoria 3031, Australia

JL Deviｌeela@unimelb.edu.au

P Zahra_pzahra@rasl.com.au

JH Vine_ jvine@rasl.com.au

T Whittem ted.whittem@unimelb.edu.au

Dr JL Devi is the corresponding author.

This is the author manuscript accepted for publication and has undergone full peer review but has not been through the copyediting, typesetting, pagination and proofreading process, which may lead to differences between this version and the Version of Record. Please cite this article as doi: $10.1002 /$ dta.2236

This article is protected by copyright. All rights reserved. 


\section{Abstract}

The doping of greyhound dogs with testosterone is done in an attempt to improve their athletic performance, but such doping cannot easily be confirmed especially in male dogs owing to the natural presence of endogenous testosterone. As testosterone is usually administered as its esters their direct detection in hair would provide confirmatory evidence of the administration of a pharmaceutical product. This paper demonstrates that the use of a liquid chromatography-high resolution mass spectrometry method with heated electrospray ionisation (HESI) combined with the use of amino SPE cartridges for sample clean up, is suitable for the sensitive determination of propionate, phenyl propionate, isocaproate, decanoate and enanthate esters of testosterone in greyhound hair. The method is linear over the range, $0.1-10 \mu \mathrm{gg} / \mathrm{kg}$, for all the testosterone esters analysed. The limits of detection (LOD) are $0.05 \mu \mathrm{g} / \mathrm{kg}$ for testosterone phenyl propionate, isocaproate and decanoate, $0.025 \mu \mathrm{g} / \mathrm{kg}$ for testosterone propionate and $0.25 \mu \mathrm{g} / \mathrm{kg}$ for testosterone enanthate. This method was applied to hair samples collected from male greyhounds before and after a single administration of a product containing several testosterone esters each of which could be detected up to 100 days post-administration. The study also demonstrates that tail hair is the specimen of choice for the analysis of testosterone in dog hair and that washing of dogs does not impact the analysis of testosterone esters in hair. This method may be useful in racing regulation for the detection of illegitimate use of testosterone in all species.

This article is protected by copyright. All rights reserved. 


\section{Keywords:}

- Testosterone ester

- LC-HRMS

- Hair

- Anabolic steroid

- Doping control

- Greyhound 


\section{Introduction}

Anabolic androgenic steroids (AAS) are derivatives or analogues of the male sex hormone testosterone, which is secreted by the testes. The AAS include many closely related ring structures and their esters. They promote the development of secondary male sexual characteristics (androgenic effects) and improve muscle growth (anabolic effects). [1] Therefore, athletes may misuse AAS to increase lean body mass, increase strength, increase aggressiveness and to shorten post-workout recovery time. Coincidentally, AAS use may lead to adverse effects such as severe cardiovascular effects and liver disease, which have been reported in young steroid abusers. [2] AAS are the preferred agents for oestrus control for bitches in greyhound racing, as they provide strong oestrus suppression with few negative side effects. However, AAS have the ability to alter the physique or psychological nature of a racing animal resulting in improved race performance. It is likely that testosterone is used as an exogenous doping agent in racing greyhounds. For this reason, with the exception of ethylestrenol when used in bitches for oestrus suppression, Greyhounds Australasia adopted an in competition ban on all AAS in July 2008. ${ }^{[3,4]}$ This has since been extended to a permanent ban on all AAS in January 2016. The suspected abuse of these drugs has led to the development of various analytical methods aimed to enable the detection and confirmation of AAS.

As testosterone is a naturally occurring endogenous hormone both in males and females, it is not commonly feasible within animal doping laboratories to differentiate analytically between exogenous and endogenous sources in canines. While isotope ratio mass spectrometry has been used for this purpose in human sports doping analysis, its application to canine samples has not yet been demonstrated. Aiming to improve the analytical detection of exogenous testosterone in samples from racing greyhounds, some in-vitro and in-vivo metabolic studies have been conducted in female greyhounds. However, very little canine data is available. ${ }^{[5]}$ Briefly, the three main metabolites found in female greyhound urine are, epiandrosterone, $5 \alpha$-androstane-3 $\beta, 17 \beta$-diol and $5 \beta$-androstane$3 \alpha, 17 \beta$-diol. [6] A collaborative study conducted in greyhounds by Racing Analytical Services Limited, Victoria and the 
University of New South Wales, Sydney (unpublished) similarly identified the same three main metabolites and Greyhounds Australasia has set a threshold at $10 \mu \mathrm{g} / \mathrm{L}$ for the metabolite, $5 \beta$-androstane-3 $\alpha, 17 \beta$-diol in female greyhound urine. In drug detection, when the exogenous analyte might also be present naturally, regulation of doping requires determination that the concentration of the analyte that is present in the sample is statistically unlikely without exogenous administration. To make this determination, regulators set a drug concentration above which the presence of a prohibited substance is declared. This pivotal concentration is called the 'threshold level'. In contrast to female greyhounds, the endogenous testosterone metabolite concentrations in males are higher, and there is more inter-individual variability. Therefore, it is difficult to define a threshold level in blood or urine and a method remains to be identified to allow declaration with certainty that a male greyhound has been dosed with a pharmaceutical preparation of testosterone.

Pharmaceutical preparations of testosterone are available in Australia with the hormone being in the chemical form of different esters. The esterified steroid improves bioavailability and prolongs the effect of the drug. The length of the ester side chain determines the water solubility of the steroid and thus impacts upon its bioavailability. Short carbon chain esters such as propionate (C3) are quickly transferred into the blood stream, leading to high concentrations and rapid clearance from the body, whereas longer chain esters, such as decanoate (C10) are released slowly and remain present at lower concentration for a longer time. After absorption from intramuscular depot the testosterone esters are hydrolysed by plasma esterases in vivo to free testosterone, which is identical to endogenous testosterone. Nevertheless, it is possible that a small quantity may be retained as the ester in any biological matrix, including hair. ${ }^{[7]}$ Therefore, if the intact testosterone-ester could be detected, it will provide unequivocal confirmation of exposure to the pharmaceutical product.

Hair specimens have been used for more than 30 years to document drug exposure in forensic, occupational and clinical situations. A major advantage of hair testing is its large surveillance time-window. ${ }^{[8,9]}$ Traditionally urine has been the matrix of choice for the detection of AASs. Gas 
chromatography-mass spectrometry (GC-MS) techniques introduced in the 1980s were capable of detecting concentrations of 1 $\mu \mathrm{g} / \mathrm{L}$ of AASs and/or metabolites in urine. Subsequently, gas chromatography combustion isotope ratio mass spectrometry (GCC-IRMS), which measures the relative composition of ${ }^{13} \mathrm{C}$ and ${ }^{12} \mathrm{C}$ isotopes, further improved detection of AASs. However, all of these methods require laborious sample preparation before analysis. ${ }^{[10]}$

Recent developments in hair extraction methods and analytical instruments have facilitated the use of hair as a matrix for the detection of AASs. Because hair is a chemically dirty matrix, the successful detection of drugs in hair requires extensive decontamination and clean up steps to reduce matrix interference thereby enabling the detection of analytes at low concentration. [11] Consequently, hair has become well established as a suitable sample for the detection of a selection of organic drugs. For example, the propionate, enanthate and decanoate esters of testosterone were identified in the hair of bodybuilders in 1999 by GC-MS. ${ }^{[12]}$ Testosterone has been detected also in the hair of steers, bulls, cows and calves by high performance liquid chromatography (HPLC) followed by enzyme immunoassay (EIA). [13] Anabolic steroids have been screened in human, cattle or racehorse hair by GCMS, GC-MS/MS, LC-MS/MS, UPLC-MS/MS and orbitrap HRMS methods. ${ }^{[7,13-16]}$ However, examples of hair analysis studies conducted for doping detection in dogs have proven difficult to identify.

In recent years, LC-MS has gained importance, as GC-MS techniques require laborious sample preparation for analysis. LC-MS methods are specific, precise and offer low limits of quantification for steroid determination. Moreover, the variability in testosterone measurements in mass spectrometry assays is smaller than in immunoassay. ${ }^{[17,18]}$

Our objective was to establish a method for the detection of testosterone esters in the hair of greyhound dogs. In this paper we report that liquid chromatography high resolution mass spectrometry (LCHRMS) in heated electrospray ionisation (HESI) mode as a suitable instrumental method for the detection of testosterone esters in dog hair following liquid/liquid extraction combined with solid phase extraction clean up with Bond-Elut amino cartridges. The method was validated for the detection of the propionate, phenyl 
propionate, isocaproate, decanoate and enanthate esters of testosterone in Greyhound hair. The applicability of the method was demonstrated by a drug administration study of the preparation, Sustanon '250', followed by analysis of collected hair at specific time intervals. Using this method, testosterone esters could be detected in greyhound hair up to 100 days post administration. The effect of shampoo washing versus no washing on the detection of esters in hair was studied and the concentrations of testosterone esters in hair from various sites were compared. We also analysed the urine to determine the concentration of testosterone and its metabolites. These data may assist in the establishment of a threshold in the future for testosterone metabolites in urine from male greyhounds.

\section{Experimental}

\section{Reagents and materials}

Esters of testosterone (propionate, decanoate, isocaproate and enanthate) were purchased from National Measurement Institute (North Ryde, NSW, Australia). Testosterone phenyl propionate, testosterone $\left(d_{3}\right)$ propionate, $\left(d_{3}\right)$ decanoate and $\left(d_{3}\right)$ enanthate were supplied by PM Separations, Capalaba, QLD, Australia). LC-grade methanol and methoxyamine hydrochloride were purchased from Sigma-Aldrich Pty Limited (Castle Hill, NSW, Australia). Acetonitrile, hexane, formic acid and ammonium formate were purchased from Rowe Scientific Pty Ltd (Doveton, Victoria, Australia); and ethyl acetate from ThermoFisher Scientific (Scoresby, Victoria, Australia). Solid phase extraction cartridges, Bond Elut $\mathrm{NH} 2$ 3cC, $500 \mathrm{mg}$ were supplied by Agilent Technologies, Australia, Pty Ltd (Mulgrave, Victoria, Australia). Sustanon '250' $\mathrm{mg} \times 1 \mathrm{~mL}$ ampoules, which contain as the active pharmaceutical ingredients, testosterone propionate (30mg), phenyl propionate (60mg), isocaproate (60mg) and decanoate (100mg), were purchased from Cenvet Pty Ltd, Australia.

Stock solutions ( $1 \mathrm{~g} / \mathrm{L})$ of individual testosterone esters were prepared in methanol and stored at $4^{\circ} \mathrm{C}$. From these stock solutions, $0.01 \mathrm{~g} / \mathrm{L}$ solutions of each of the testosterone esters and deuterated testosterone esters were prepared separately. Mixed standard stock solutions containing $0.1 \mathrm{mg} / \mathrm{L}$ of each testosterone ester were prepared. These were again diluted in methanol to obtain spiking solutions of appropriate concentrations. For the internal standard, $0.01 \mathrm{mg} / \mathrm{L}$ mixtures 
of deuterium-labelled testosterone esters were prepared in methanol and $10 \mu \mathrm{L}$ of each solution (equivalent to $0.001 \mathrm{mg} / \mathrm{Kg}$ of hair) was added to the sample tubes.

\section{Experimental animals}

The animal experiment study was conducted at the dog colony facility in the Faculty of Veterinary and Agricultural Sciences, University of Melbourne, after prior approval from the University of Melbourne Animal Ethics Committee. Six adult male, retired racing greyhound dogs were used for the study. The dogs were kept in quarantine for 14 days, and thereafter transferred to the dog colony. Initial examination and haematology confirmed their health and all dogs were enrolled in the study. The dogs did not receive any drug treatment for more than 1 month prior to the study. One of the six (1/6) dogs was excluded from the study after study initiation for welfare reasons, as its tail was injured early in the study period. The dogs were fed and cared for using standard operating procedures for the dog colony.

\section{Conduct of the experiment}

The dogs were exercised on a dog treadmill to simulate race fitness in a four-dog walking machine (Movitrac IT). To habituate the dogs to the treadmill, the dogs were adapted to the walking machine for four days at a slow walking pace of 2 $\mathrm{m} / \mathrm{s}$ and thereafter increasing to $4 \mathrm{~m} / \mathrm{s}$. Once adapted to the treadmill, the dogs were walked no less than twice each week on the treadmill at $4 \mathrm{~m} / \mathrm{s}$ and this exercise regime was continued throughout the experiment.

To evaluate the effect of washing the dogs on the persistence of the drugs in hair, the left sides of the dogs were washed with a mild shampoo once a week and the right sides remained unwashed.

Sample of hair and urine were collected according to a predetermined schedule; initially before drug administration, and post-administration every second day for one week (4 time points) then weekly for one month (4 time points), then fortnightly up to 3 months post dosing (4 sample time points) for a total of 13 sample time points per dog.

Free catch midstream urine was collected in kidney trays, and stored in duplicates in $70 \mathrm{~mL}$ specimen vials at $-70^{\circ} \mathrm{C}$. 
Baseline hair samples (10-12 mm long) were harvested using a motorised hair clipper by clipping a small patch from both the right and left lateral thorax (chest wall), which was the primary hair sample. Prior to hair clipping the dogs were thoroughly brushed. These full-length hair samples were collected into aluminium foil paper and transferred to $70 \mathrm{~mL}$ specimen vials. Care was taken to avoid cross contamination: between dogs the hair clipper was cleaned with cotton wetted with $70 \%$ Ethanol. Hair samples were also collected from other zones of the dogs' bodies; body of tail, base of tail, and right and left abdomen following the above method. These samples were divided into two equal portions, and stored at $70^{\circ} \mathrm{C}$ until analysis.

After the pre-drug administration sample collection, the dogs were injected intramuscularly with Sustanon'250' at a dose rate, which approximates the recommended therapeutic dose of testosterone products for dogs. A dose of $0.45 \mathrm{~mL}$ of Sustanon '250' which contained 3-4 mg/kg of testosterone was administered to each dog. The dose in milligrams of each of the testosterone esters-propionate, phenyl propionate, isocaproate and decanoate in Sustanon '250' which a dog had received in the administered dose of $0.45 \mathrm{~mL}$ is $13.5,27,27$ and 45 respectively. Post-drug administration samples of hair from the adjacent sites in the vicinity of the above-mentioned sites and urine were collected according to the planned schedule.

Pre- and post-drug administration samples of hair and urine collected at various time points from five dogs were analysed by applying the analytical procedure, which was developed.

\section{Sample preparation and analysis in hair}

The sample preparation and instrumentation method was based on the method of Gray et al but significant modifications were made to improve its efficiency and sensitivity for greyhound hair. [7] The extracts were quantified with an eight-point calibration curve $(\odot-1 \odot \mu \mathrm{g} / \mathrm{kg})$ alongside quality control samples (containing the propionate, phenyl propionate, isocaproate, decanoate and enanthate esters of testosterone).

Hair samples were initially washed by being placed in glass tubes and covered with hexane, then vortex-mixed for 3 minutes. Supernatant hexane was removed and the hair was dried on whatman filter paper. The hair was then cut into sections 
of less than $5 \mathrm{~mm}$ and stored at $4{ }^{\circ} \mathrm{C}$ in $20 \mathrm{~mL}$ glass scintillation vials until analysis.

Approximately, $100 \mathrm{mg}$ of dried hair was weighed into $16 \times 100$ mm KIMAX screw cap glass culture tubes (Rowe Scientific, Australia). A $10 \mu \mathrm{L}$ volume of $0.01 \mathrm{mg} / \mathrm{L}$ solution of mixed internal standards (equivalent to $1 \mu \mathrm{g} / \mathrm{kg}$ of hair) was added to each tube followed by $4 \mathrm{~mL}$ of $0.1 \mathrm{M}$ phosphate buffer at $\mathrm{pH}$ 9.5. The sample was then ultrasonicated for $60 \mathrm{~min}$, to achieve disruption, as complete digestion is likely to result in destruction of the target analytes. The analytes were extracted by liquid-liquid extraction with $2 \times 4 \mathrm{~mL}$ of hexane: ethyl acetate $(7: 3, \mathrm{~V} / \mathrm{V})$. The organic phases were evaporated to dryness and the dried residue were dissolved in $2 \mathrm{~mL}$ ethyl acetate for further clean up by solid phase extraction (SPE) using Bond Elut NH2 cartridges, 3cc (500mg) (Agilent Technologies), with the aid of a Gilson GX-274 APSEC workstation. The sample residues in ethyl acetate were loaded onto cartridges previously conditioned with hexane $(3 \mathrm{~mL})$. The flow through from the sample-loading step was collected. The sample tube was again rinsed with ethyl acetate $(2 \mathrm{~mL})$ and loaded onto the cartridge and collected. The eluates were evaporated to dryness and $100 \mu \mathrm{L}$ of $100 \mathrm{mM}$ methoxyamine hydrochloride in $80 \%$ methanol (aqueous) was added. After a brief vortex mixing, the extracts were transferred to glass vials with low volume inserts (Phenomenex, Verex, $9 \mathrm{~mm}$ screw, micro vial 13 (QSert), clear 33). Derivatisation was achieved by placing the vials in a dry block heater at $80^{\circ} \mathrm{C}$ for an hour, to form the methyloxime derivatives of the testosterone esters. A $10 \mu \mathrm{L}$ volume of the final derivatised extract was injected into the LC-MS/MS system.

\section{Instrumentation}

Analysis was carried out on a Thermo Scientific Q Exactive mass spectrometer coupled with a Shimadzu LC-30AD liquid chromatography system, which included a quaternary pump, online degasser, and an autosampler. Chromatographic separation was performed on a Poroshell 120 EC-C18 column (3 $\mathrm{mm} \times 50 \mathrm{~mm}, 2.7 \mu \mathrm{m}$ particle size) at a temperature of $30^{\circ} \mathrm{C}$. Solvents were $0.1 \%$ formic acid:0.1\% ammonium formate $(1: 1$ $\mathrm{V} / \mathrm{V})(\mathrm{A})$ and Methanol: Acetonitrile (25:75)(\%)(B). Initial conditions were $80 \% \mathrm{~B}$ which was ramped to $98 \%$ over 5 minutes and held for 3 minutes before returning to $80 \%$ over 1 minute. 
The column was equilibrated for 3 minutes. The flow rate was $0.6 \mathrm{~mL} / \mathrm{minute}$ and the injection volume was $10 \mu \mathrm{L}$.

The Q Exactive was operated in heated electro spray ionisation (HESI) mode with an ion spray voltage of $3000 \mathrm{~V}$, vaporizer temperature of $350^{\circ} \mathrm{C}$, capillary temperature of $360^{\circ} \mathrm{C}$, sheath gas at 50 units, auxiliary gas at 20 units and ion sweep gas at $\odot$ units. The $\mathrm{Q}$ Exactive was operated in targeted $\mathrm{MS}^{2}$ mode. The resolution was set at 35,000. Data processing was performed using the Excalibur software. Analytes were characterised using two high-resolution accurate mass product ion chromatograms (HRAM chromatograms) for each analyte as shown in Table 1.

\section{Method Validation}

The analytical method was validated and verified using the inhouse guidelines of Racing Analytical Services Limited, Victoria that operates under ISO/IEC 17025. The method was validated for sensitivity, selectivity, precision, accuracy, extraction recovery, ruggedness, matrix effects and linearity. Validation was carried out on three different days by three individuals by analysing an eight point calibration graph alongside ten replicates of blank hair (100 mg) spiked with known concentrations of testosterone-ester mix containing 0.1 $\mu \mathrm{g} / \mathrm{kg}$ each of all the esters of testosterone except enanthate, which was added at a concentration of $0.5 \mu \mathrm{g} / \mathrm{kg}$. The validation parameters for LC-MSMS in hair are shown in Table 2. Linearity was determined over the concentration range, 0.1 $10 \mu \mathrm{g} / \mathrm{kg}$; the method was shown to be linear in hair samples over the range, $0.1-10 \mu \mathrm{g} / \mathrm{kg}$. The coefficients of determination $\left(R^{2}\right)$ were greater than 0.99 for all the testosterone esters analysed. The inter-day and intra-day precision, accuracy and sensitivity were calculated using the ten replicates of spiked blank hair run alongside the calibration graph. The LOD was defined as the concentration for which the signal-to-noise ratio was $>3$. The LOQ was defined as the lowest concentration, which produced a precision and accuracy of less than $20 \%$ ( $20 \%$ CV). Selectivity of the method was determined by analysing $>20$ independent analyte-free hair samples from greyhound dogs. The hair samples were checked for possible interferences from any endogenous substances by monitoring the high resolution accurate mass (HRAM) chromatograms characteristic of each testosterone ester being investigated, at the retention time interval expected for its elution. The extracted ion 
chromatogram obtained from a control hair sample, hair spiked with $5 \mu \mathrm{g} / \mathrm{kg}$ of testosterone ester mixture, hair spiked at LOQ and tail hair 98 days after drug administration is shown in Figures 1,2,3 and 4 .

To determine the extraction recovery, blank hair samples (100 mg) were either pre-spiked (before digestion) or post spiked (after extraction) with testosterone esters at a concentration of $10 \mu \mathrm{g} / \mathrm{kg}$ and extracted and analysed as described. Extraction recovery was calculated as the ratio of the target analyte peak area for hair samples spiked before digestion versus the area obtained for the same quantity of standard spiked post extraction. Ion suppression due to matrix components was calculated as the ratio of the target analyte peak area for hair samples spiked post extraction versus the area obtained for the same quantity of standard spiked into mobile phase.

\section{Detection in hair samples and pharmacokinetic analysis}

The analytical procedure was applied to the analysis of hair samples collected. The primary hair samples chosen for analysis were the right chest hair samples, as the right side of the animals were not washed with the shampoo. Hair samples were analysed to determine the maximum observed concentration $\left(\mathrm{C}_{\max }\right)$ and time point at which maximum concentration was observed $\left(T_{\max }\right)$. The data analysis for hair samples was performed by non-compartmental analysis using a combined linear trapezoidal rule approach (Model 200-202, Phoenix WinNonlin 4.1; Certara, USA, Inc). The first order disappearance rate constant $(\lambda z)$ was calculated as the slope of the terminal (log linear) segment of the curve, estimated using linear regression. The terminal disappearance half-life $t_{1 / 2}$ was calculated as $0.693 / \lambda z$. The $\mathrm{C}_{\max }$ and $\mathrm{T}_{\max }$ were determined directly from the data.

\section{Determination of testosterone and metabolites in urine}

Urine samples collected from all five dogs were analysed for testosterone and its metabolites using the existing routine screening GC-MS method, which had been previously validated according to in-house guidelines and is accredited to ISO/IEC 17025. The metabolites of testosterone detected were; $5 \beta$ - 


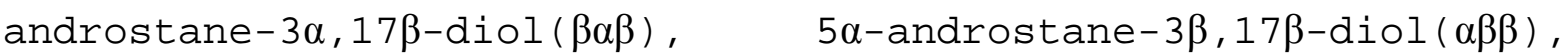
epiandrosterone, $5 \alpha$-androstane-3 $3,17 \alpha-d i o l(\alpha \beta \alpha)$, epitestosterone, testosterone and etiocholanolone. Standard calibration samples at spiked concentrations of $2.5,5,10$ and $20 \mu \mathrm{g} / \mathrm{L}$ were analysed on each day along with the urine samples.

\section{Results and Discussion}

\section{Optimisation of Solid phase extraction}

During method development the various steps of the hair analysis were investigated in order to maximise the sensitivity of the method. Dog hair is a chemically dirty matrix and causes severe signal suppression for the analytes leading to poor sensitivity in detection. This necessitated the optimisation of the washing steps, hair digestion and post digestion clean up.

Washing was optimised to minimise the potential for false positive results caused by the presence of analytes on the surface of the hair as a result of passive contamination. Washing was also optimised to reduce possible hair digestion during the washing steps. The effect of various decontamination solvents- hexane, isopropanol, 20\% methanol, acetone and dichloromethane on hair collected from another dog that had previously been administered testosterone propionate were evaluated. This showed that non-polar solvents like hexane and diethyl ether resulted in sequential decrease of testosterone propionate concentration in various washes followed by increase in concentration in the hair extract. It was found that more polar solvents such as isopropanol and $20 \%$ methanol were potentially digesting the hair, as successive washes did not result in a sequential decrease of testosterone propionate concentration in washes but rather a constant concentration in three successive washes. It is also likely that these solvents were opening up the cuticle structure and lead to extraction of drug from the interior of the hair shaft. As testosterone propionate is lipophilic in nature the efficiency of the extraction could be poor with these solvents and therefore consistent concentrations were observed for successive washes.

After final optimization, hexane was selected as the washing solvent. Previously, other washing methods; $20 \%$ methanol, acetone, dichloromethane followed by ultrasonication for 15-30 
minutes had been either adopted or tried by other research groups in UHPLC methods. $\left.{ }^{7}, 19,20\right]$ Our washing method procedure is relatively quick, as it requires only vortexing for 3 minutes after addition of hexane, followed by drying of the hair.

Several methods for the digestion and extraction of hair were investigated. We initially tried weak alkaline digestion followed by liquid/liquid extraction and SPE clean up, following the method employed by Gray et al. ${ }^{[7]}$ Although this method when replicated for canine hair produced excellent recoveries, the absolute sensitivity of the method was severely affected by large amounts of ion suppression for all the analytes. The ion-suppressing agents present in the greyhound hair extracts must have been co-eluting with the testosterone esters being monitored. This also means that they may be likely similar in polarity to the esters, with possible differences in functionality. We therefore decided to try a sorbent that could exploit minor differences in polarity and functionality to separate the ion-suppressing agents from the testosterone esters. Amino cartridges have been successfully used previously to separate lipid classes as in fractionating of cholesteryl esters, free fatty acids and cholesterol from bovine adipose tissue extracts. ${ }^{[21]}$ Amino cartridges have also been used for the purification of steroids in hair extracts by reported fixation of ionized impurities on the amino cartridge sorbent. [22] The use of the amino cartridge successfully reduced ion suppression from greater than 90\%(with HLB cartridge) for all esters to as low as $20 \%$ for testosterone propionate and as high as $40 \%$ for testosterone decanoate. This enabled to lower the LOD significantly.

As anabolic steroids have hydroxyl and keto groups in their structure they do not always exhibit good chromatographic behaviour. Derivatisation can improve both the ionisation efficiency and the chromatography of steroids. For 3-keto steroids the formation of oximes provides significant advantages. ${ }^{[7]}$ Therefore derivatisation of the 3 -ketone group of the testosterone esters with methyloxime was employed for this assay

\section{LC-MSMS optimisation}

A LC column utilising non-porous particles was chosen to reduce run time and increase sensitivity, through the reduction of peak width and associated increase in peak 
height. Different mobile phase solvent combinations routinely used in our laboratory were tried but produced high background noise. Ultimately, the addition of acetonitrile to the organic phase of the solvent system employed was found to provide optimum sensitivity, due to a significantly lower baseline compared with an organic phase consisting of methanol only.

For MS/MS analysis each testosterone ester was identified using two high-resolution accurate-mass product ion transitions, together with their specific LC retention times. The ionisation techniques commonly used in LC-MS analysis of steroids include APCI (atmospheric pressure chemical ionisation), APPI (atmospheric pressure photo ionisation) and ESI (Electrospray ionisation). Heated electrospray ionisation (HESI) and APCI were compared. It was found that HESI provided greater sensitivity when compared with APCI.

\section{Incurred hair sample drug concentration}

All of the testosterone ester concentrations in the preadministration hair samples were below detection limits, except for testosterone propionate and testosterone isocaproate in Dog 1 , which were $0.31 \mu \mathrm{g} / \mathrm{kg}$, and $0.05 \mu \mathrm{m} / \mathrm{kg}$ respectively (Table 3 ). This positive detection of two testosterone esters in Dog 1 at time zero is likely to have been caused by in-laboratory contamination. In support of this explanation, it was noted that the blank hair used in this analysis, which had been previously tested negative for the testosterone esters, was also positive for the detection of testosterone isocaproate. Unfortunately, there was insufficient hair sample remaining for the repetition of the analysis. After the pre-administration hair sample analysis, the post-administration hair samples collected from the right chest were analysed. All the testosterone esters were detected above their quantification limits $(>0.1 \mu \mathrm{g} / \mathrm{kg})$ from 2 hours post administration, which was the first sample collected after drug administration. The results showed that $\mathrm{C}_{\max }$ was observed on day 2 in all five dogs, except for testosterone propionate, where $\mathrm{C}_{\max }$ occurred on day 2 in dogs 1 and 3 , day 4 in $\operatorname{dog} 2$ and 5 , and on day 8 in Dog 4. Thereafter drug concentrations in hair declined over the 77 days after dosing (Table 4, Figure 5). All the testosterone ester concentrations were above the lower limit of quantification in all the five dogs up to 21 days and thereafter were quantifiable only in some of the dogs. Nevertheless, when the esters were not 
quantifiable in some of the dogs the testosterone esters were still detectable for up to 91 days (Table 6).

The detection of testosterone esters from as early as 2 hours post administration in all the dogs was not expected. The testosterone esters detected at this time point must have been adsorbed onto the hair from sebum or sweat rather than incorporated during hair growth as hair grows too slowly for these detections to have been due to deposition within the follicle. As the hair was collected using clippers, the root and portion of the hair shaft under the skin would be still in place and the hair collected at the first sample time point would have formed days to weeks before the administration. Many mechanisms have been proposed for the incorporation of drug in hair. It has been proposed that drugs could be incorporated into hair from blood via the hair follicle, incorporated from sweat via the hair shaft, absorbed from sweat on the outside of the hair shaft, and/or absorbed from exogenous sources such as environmental contamination. From our observations, the early detection of steroid esters supports the multiple pool model of drug accumulation, wherein the steroid esters are adsorbed from sweat on the outside of hair shaft (endogenous-exogenous pathway) and it may be loosely bound to the hair. [22-24]

Another possibility for detection at this time point is that it could be due to external contamination. However, as it is clear from the results that the baseline hair samples were free from the testosterone esters (except as explained for one dog on one analytical occasion) and all the esters were present in high concentrations in all five dogs at 2 hours post-administration of Sustanon 250, the possibility of an external contamination seems to be quite unlikely.

It was observed in our study that testosterone esters could be detected above the LOD for longer periods in primary chest hair samples (91 days), even while they were not quantitated (Table 6). For the purpose of detection of testosterone as a doping agent in racing regulation, mere identification of an intact testosterone ester is enough to document a positive exogenous testosterone administration.

\section{Choice of tail hair as the site for hair collection}

Several groups have studied the variation of drug concentration in hair from different sites in humans and 
different results have been reported for different drugs. In humans, concentration of methadone, opiates, methamphetamine and cocaine vary in hair collected from different sites. [25, 26] Due to the ease of collection and the lesser variability in growth rate, head hair is considered the best sample for analysis in humans. In horses, mane and tail hair are the usual samples of choice for hair collection, probably because hair from those sites in horses is more permanent. ${ }^{[9,}{ }^{27]}$

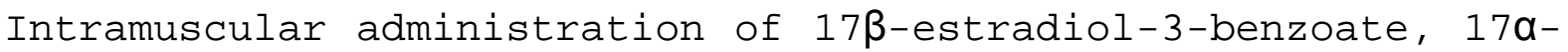
methyltestosterone and medroxyprogesterone acetate in the neck of cattle allowed examination of hair from the head, neck, abdomen, rump, and tail. It was demonstrated that medroxyprogesterone acetate was not found in the hair from any of these sites. For 17 $\beta$-estradiol-3-benzoate, head and neck hair were reported to be the most suitable materials for detection as steroid concentrations were high and detection time was prolonged. However, for 17a-methyltestosterone, neck and abdomen hair provided the most efficient detection. [28] Studies on the persistence of oestradiol benzoate and nortestosterone decanoate in hair from cattle was investigated and it was reported that steroid ester concentrations in hair were related to the distance of the sampling site from injection, as a decrease in ester concentration was observed further from the injection site. [29] We are unaware of published studies that compare the extent of drug deposition in hair from various sites in dogs.

To determine the most effective site for the collection of hair for doping analysis the 77 and 91 days postadministration hair samples from right chest, right abdomen, tail and base of tail were analysed. It was noted that in most dogs (Dog 1, 2 and 4) the esters could be detected in higher concentration in tail hair compared with hair from the chest and abdomen. Only in Dog 5 was testosterone propionate detected in hair from all the sites, with the highest concentration being in hair from the abdomen and equal concentrations in chest and tail hair. The mean concentration of testosterone esters in the hair from the tail $(n=5)$ was much higher compared with hair from the right chest and right abdomen. As the tail seemed to be a potentially favourable site for hair collection for testosterone ester detection, the tail hair samples on days 91, 98 and 100 were also analysed. A slight increase in the mean concentration of testosterone esters in 5 dogs was noticed on Day 91, but there was no definite pattern of increase between individual dogs on the 
different days. Table 5 shows the number of dogs in which the analytes were quantified and detected in tail hair at 77,91 , 98 and 100 days. In the dogs where the testosterone esters were not detected in the 77 day tail hair samples, they become detectable again in the 91 day samples, similar to what had been noted in chest hair samples. Nevertheless, the testosterone esters could be detected even up to 100 days post administration in tail hair. This demonstrates that tail hair is the best choice for hair collection in order to maximise the possibility of regulatory drug detection.

There are three factors, which may facilitate the higher drug incorporation in tail hair. Firstly, apocrine secretions may be higher in the perineal area compared with other sites thereby increasing drug incorporation onto hair from sweat or sebum. Secondly, the tail hair is nearer to the injection site in the hind leg than the hair from the other sites sampled and a study in cattle showed that there was a decrease in concentration of testosterone esters farther from the injection site. [29] Finally, it is possible that the hair growth cycle, which may comprise a longer anagen stage or a faster hair growth rate in the tail hair, could allow for increased incorporation of drug into the hair shaft.

Hair growth cycles have been studied in beagle dogs. Unlike humans, dogs have compound follicles consisting of a primary and several secondary hairs, which exit through the same orificium. The primary hairs have an arrector pili muscle and both sebaceous and apocrine glands. Compound follicles join together and form follicular units. The different hair follicles of one compound cycle are independent of each other. The duration of the anagen and telogen cycle may differ between species, breed and seasonal variations.[30]

In our study, intramuscular injection into the semimembranosus or semitendinosus muscles was used. Although the tail is nearer to this injection site than the flank, the base of the tail compared with the tail shaft hair did not show any increased concentration of the analytes. This demonstrates that proximity to the injection site is not likely to be the sole reason for higher drug incorporation rate in tail hair.

\section{Influence of polarity and lipophilicity of the esters on detection times}


The ester side chain length affects the steroid's water solubility and influences its bioavailability. Shorter carbon chains such as propionate are transferred into and cleared from the blood stream and the body more quickly. Longer chain esters such as decanoate are absorbed more slowly and are retained in the body at lower concentrations for a longer period of time. ${ }^{[7]}$

Table 7 shows the duration for which the different testosterone esters were detected above LOD, in hair samples from the right chest area. All testosterone esters were detected above quantification limits (LOQ) until 21 days. The analytes remained above their limits of detection (LOD) in later time points. Testosterone propionate could be detected in two dogs up to 91 days post-administration. Testosterone phenyl propionate was detected above the LOQ at 35 days in 4/5 dogs, and in $1 / 5 \mathrm{dog}$, at 63 and 77 days.

Testosterone isocaproate is less polar than testosterone phenyl propionate as evidenced by their octanol-water partition coefficients of 5.5 and 5.8, respectively. Testosterone isocaproate could be quantified for up to 35 days in $3 / 5$ dogs. In two dogs testosterone decanoate was quantified up to 35 days post-administration after which time, it was not quantifiable in any of the dogs. However, it was detected again at 63 days in Dog 1 (Table 6). This is consistent with the previous report of Durateston administration in the horse, where testosterone propionate and testosterone decanoate were once again detected after failure to detect in earlier time points. ${ }^{[7]}$

Contrary to theoretical expectations, the longest detection time window was not seen with the less polar testosterone decanoate, despite the $\mathrm{C}_{\max }$ of testosterone decanoate being approximately equal to that of the other testosterone esters. Therefore, we hypothesize that factors other than polarity influence the deposition and persistence of testosterone esters in hair, e.g., testosterone decanoate may bind less effectively or may degrade faster in hair.

Our observations support the findings in 2009, that lipophilicity is not the sole factor influencing the incorporation of testosterone esters into or onto hair. [31] It may be that the more polar ester is incorporated into the polar hair matrix more efficiently. In addition, an aqueous 
phosphate buffer is used during the extraction procedures for hair may cause a higher recovery for short chain carbon esters like testosterone propionate.

\section{Effect of shampoo washing on the drug concentration in hair}

The effect of shampoo washing in human hair was previously reported, not to significantly affect the drug content in hair. ${ }^{[32,33]}$ It has also been demonstrated that, after a single shampoo wash of human hair, contaminating drugs were not completely removed, and they were still present above detection limits. Continued shampoo treatment of human hair contaminated with drugs has also been shown not to produce any significant change in the concentration of cocaine in the washed hair sample and that the effect of shampooing is only decontamination.[34, 35] However, dyeing, bleaching and perming have been previously reported to decrease drug concentrations in human hair. [36, 37]

To study the effects of shampooing dogs on drug concentrations in their hair, the day 63 and 77 samples from the right (unwashed) and left (shampoo washed) sides of the chest from the five dogs were analysed. In general, the testosterone ester concentrations in Dog 1 were higher compared with the other dogs (Table 8). From the results of the paired $t$ tests for the difference in testosterone ester concentration in washed versus unwashed hair it was concluded that, for testosterone propionate and testosterone phenyl propionate at day 63, washing with shampoo significantly altered the drug concentration. On day 77 too, testosterone propionate concentration was significantly altered by washing. Unexpectedly, the effect of washing was to increase the concentration of esters detected in the extracts from the hair, an effect that remains unexplained. It could be explained that the increase in ester concentrations in the shampooed samples was due to reduced matrix interference from sweat or sebum in the hair. As there were not enough dogs in which testosterone isocaproate and testosterone decanoate were detected in hair collected at these times, those esters could not be compared before and after shampooing. However, it was concluded that shampoo treatment of greyhound dogs is not an obstacle to detection of testosterone esters in hair. 


\section{Effect of decontamination washes on the detection of steroid esters}

Testosterone and testosterone esters are reported to be incorporated into hair but not chemically linked to the melanin pigment. Therefore, the esters might be removed by hair washing as proposed by Anielski. ${ }^{[23]}$

In the greyhound racing industry, a potential defense for violative hair detection of steroids may be to claim that the dog's hair was passively exposed from environmental sources. However, in some jurisdictions this issue is redundant, now that a permanent ban on anabolic steroids is in place. There is no reason why a dog should be exposed to a substance that has no place in a kennel. Ideally, decontamination solvents should remove the contaminants, but not extract drugs from the hair matrix. Therefore, a thorough examination of the wash solutions obtained during hair decontamination is required. This led us to analyse the wash solutions for some of the samples.

To analyse the effect of decontamination washes on the hair analysis, the 100 day post administration tail hair samples from three dogs (Dogs 1, 3 and 5) were washed twice with hexane and then with isopropanol following the same manner as described for the sample preparation. The wash solutions were dried under nitrogen at $60^{\circ} \mathrm{C}$ and the residues were analysed. Generally, these were positive for all the testosterone esters with a sequential decrease of drug concentration. Only in the case of Dog 5, was there also a decrease in testosterone isocaproate and decanoate concentration in the hair extract, when compared with the concentration in the third (isopropanol) wash. The hair analysis was repeated for the 98day post-administration samples with similar results.

It has been proposed that a drug, which has been applied to hair by external contamination, may be more easily removed by early washes than drug that has been incorporated into hair. If this hypothesis were true, our results suggest that some external contamination had occurred. [38] However, all of the dogs in the study were housed separately and they were brought separately to the treatment room for sample collection. All the dogs were groomed with a brush, before clipping the hair. The hair clipper used for sample collection was cleaned using $70 \%$ ethanol and dried between sample collections. Therefore, cross contamination between animals was unlikely. 
Nevertheless, the measured concentrations decreased in sequential washes and then finally increased in the final hair extract. While it is possible that the concentration of the analytes detected in the hair samples could be a combination of analytes due to both passive exposure and from incorporation in the hair, it is more likely there are multiple binding sites for drugs in and on hair with different affinities for testosterone esters. Future work may be needed to develop and improve the washing steps.

To investigate the unexpected detection of esters at the early time points of the "Sustanon" administration we conducted additional experiments. Hair samples collected 2 hours and 2 days post administration of Ropel (testosterone enanthate) were subjected to these further washing experiments. The 2hour post administration hair was subject to two hexane washes and the 2-day post administration hair sample was subject to two hexane washes followed by an isopropanol wash. The washes and hair samples were analysed as described above. Once again a sequential decrease in testosterone enanthate concentration with each wash was found. However, an increase in testosterone enanthate concentration in the hair extract, in comparison to the last wash, was not found. If the esters were incorporated more tightly within the hair an increase in ester concentration in the hair extract, compared with the final wash would be expected. Therefore, we interpret this finding as an indication that the presence of esters on hair at these early time points is due to the esters being deposited on the hair through sweat or sebum and becoming loosely bound to the hair. It also demonstrates that the approach using wash ratios as a criterion to differentiate passive contamination from active exposure may not be applicable for anabolic steroid esters.

\section{Detection of metabolites in urine}

Urine is the main matrix used for the detection of testosterone in greyhound dogs. As the testosterone esters are highly lipophilic, they are not usually detected in urine where they are instead detected as their water soluble metabolites or conjugates. ${ }^{[39]}$

In the current study it was noted that, in contrast with the testosterone metabolite concentrations in untreated normal female greyhound dogs, the metabolite concentrations prior to dosing were higher in male dogs, as testosterone is an 
endogenous hormone (Table 10)(Table 11). The mean concentration of testosterone and its metabolites in five dogs after drug administration is shown in (Table 12). The concentration of the metabolites was at a maximum in urine at 48 hours post-administration and thereafter declined. Three metabolites were detected for up to 91 days. However, establishing a threshold for the metabolite concentration for detection of positive drug exposure is not possible from this study, as we did not have sufficient numbers of male greyhound dogs.

\section{Conclusions}

This paper demonstrates that LC-HRMS in HESI mode is a technique suitable for the detection of testosterone esters in dog hair following solid phase extraction with Bond Elut amino cartridges. This is the first time a method has been reported for the detection of testosterone esters in hair of canines. This LC-HESI-MS/MS method is fully validated and the data demonstrate that it has a wide linear range for quantification. The method is sensitive with a LOD for the three testosterone esters, phenyl propionate, isocaproate, and decanoate of $0.05 \mu \mathrm{g} / \mathrm{kg}$ and an LOD for the propionate of 0.025 $\mu \mathrm{g} / \mathrm{kg}$. Testosterone enanthate alone has a LOD of $0.5 \mu \mathrm{g} / \mathrm{kg}$. The utility of hair analysis has been demonstrated to detect a single administration of an ester preparation. This method has a long detection time window and the testosterone esters could be detected for up to 100 days after drug administration. In addition, the study showed that tail hair incorporates the esters more than hair from other body sites.

Hair analysis may find useful application in drug detection for the confirmation of the use of testosterone in both male and female greyhound dogs, where it may have been used to improve racing performance. Detection of the intact testosterone ester confirms that a drug product has been administered to the animal. However, the regulation of anabolic steroid esters in racing using this method for longterm detection of the anabolic steroid esters may be complicated where out-of-competition use of these agents is permitted. From the current study it is not possible to estimate the time of testosterone ester administration. However future work could be targeted at segmental hair analysis to allow estimation of the time of administration of the drug. 


\section{Acknowledgements}

This work was funded by Greyhound Racing Victoria Limited, Australia. The authors also wish to thank Dr. Leilani Santos, and $\mathrm{Dr}$. Deepthi Leelamany for their research assistance.

\section{References}

[1] Yesalis. Anabolic steroids in sport and exercise Champaign, IL : Human Kinetics Publishers, 1993.

[2] G.D.R. H.A Haupt. Anabolic Steroids: A review of literature. Am. J. Sports Med. 1984, 12,

[3] A.R. McKinney, A.T. Cawley, E.B. Young, C.M. Kerwick, K. Cunnington, R.T. Stewart, J.I. Ambrus, A.C. Willis, M.D. McLeod. The metabolism of anabolicandrogenic steroids in the greyhound. Bioanalysis. 2013, 5, 769.

[4] L.L. Blythe, J.R. Gannon, A.M. Craig. Care of the racing greyhound : a guide for trainers, breeders and veterinarians 1994.

[5] T.M. Williams, A.J. Kind, W.G. Hyde, D.W. Hill. Characterization of urinary metabolites of testosterone, methyltestosterone, mibolerone and boldenone in greyhound dogs. Journal of Veterinary Pharmacology \& Therapeutics. 2000, 23, 121.

[6] S. Biddle, A. O Donnell, J. Peterson, W. Hyde, E. Houghton. Monitoring the use of anabolic oestrus suppressants in the racing greyhound bitch: testosterone. Proceedings of the 15th International Conference of Racing Analysts and Veterinarians. 2005, 107.

[7] B.P. Gray, M. Viljanto, J. Bright, C. Pearce, S. Maynard. Investigations into the feasibility of routine ultra high performance liquid chromatography-tandem mass spectrometry analysis of equine hair samples for detecting the misuse of anabolic steroids, anabolic steroid esters and related compounds. Anal. Chim. Acta. 2013, 787, 163.

[8] A.M. Baumgartner, P.F. Jones, W.A. Baumgartner, C.T. Black. Radioimmunoassay of Hair for Determining Opiate-Abuse Histories. J. Nucl. Med. 1979, $20,748$.

[9] T. Whittem, C. Davis, G.D. Beresford, T. Gourdie. Detection of morphine in mane hair of horses. Aust. Vet. J. 1998, 76, 426.

[10] S. Strano-Rossi, C. Fiore, M. Chiarotti, F. Centini. Analytical techniques in androgen anabolic steroids (AASs) analysis for antidoping and forensic purposes. Mini Reviews In Medicinal Chemistry. 2011, 11, 451.

[11] T. Baciu, F. Borrull, C. Aguilar, M. Calull. Recent trends in analytical methods and separation techniques for drugs of abuse in hair. Anal. Chim. Acta. 2015, 856, 1.

[12] P. Kintz, V. Cirimele, H. Sachs, T. Jeanneau, B. Ludes. Testing for anabolic steroids in hair from two bodybuilders. Forensic Sci. Int. 1999, 101, 209.

[13] A. Gleixner, H.H.D. Meyer. Detection of estradiol and testosterone in hair of cattle by HPL/EIA. Fresenius' J. Anal. Chem. 1997, 357, 1198.

This article is protected by copyright. All rights reserved. 
[14] N. Deshmukh, I. Hussain, J. Barker, A. Petroczi, D.P. Naughton. Analysis of anabolic steroids in human hair using LC-MS/MS. Steroids. 2010, 75, 710.

[15] J. Segura, S. Pichini, S.H. Peng, X. de la Torre. Hair analysis and detectability of single dose administration of androgenic steroid esters. Forensic Sci. Int. 2000, $107,347$.

[16] S. Strano-Rossi, E. Castrignanò, L. Anzillotti, S. Odoardi, F. De-Giorgio, A. Bermejo, V.L. Pascali. Screening for exogenous androgen anabolic steroids in human hair by liquid chromatography/orbitrap-high resolution mass spectrometry. Anal. Chim. Acta. 2013, 793, 61.

[17] M.M. Kushnir, A.L. Rockwood, J. Bergquist. Liquid chromatography-tandem mass spectrometry applications in endocrinology. Mass Spectrometry Reviews. 2010, $29,480$.

[18] H.W. Vesper, S. Bhasin, C. Wang, S.S. Tai, L.A. Dodge, R.J. Singh, J. Nelson, S. Ohorodnik, N.J. Clarke, W.A. Salameh, C.R. Parker Jr, R. Razdan, E.A. Monsell, G.L. Myers. Interlaboratory comparison study of serum total testoserone measurements performed by mass spectrometry methods. Steroids. 2009, 74, 498.

[19] P. Aqai, A.A.M. Stolker, J.J.P. Lasaroms. Effect of sample pre-treatment on the determination of steroid esters in hair of bovine calves. J. Chromatogr. A. 2009, $1216,8233$.

[20] M.W.F. Nielen, A.W.J.M. Nijrolder, H. Hooijerink, A.A.M. Stolker. Feasibility of desorption electrospray ionization mass spectrometry for rapid screening of anabolic steroid esters in hair. Anal. Chim. Acta. 2011, 700, 63.

[21] L.A.D. M.A. Kaluzny, M.V. Merritt, D.E. Epps. Rapid separation of lipid classes in high yield

and purity using bonded phase columns. J. Lipid Res. 1985, 26,

[22] Y. Gaillard, F. Vayssette, A. Balland, G. Pépin. Gas chromatographic-tandem mass spectrometric determination of anabolic steroids and their esters in hair: Application in doping control and meat quality control. Journal of Chromatography B: Biomedical Sciences and Applications. 1999, 735, 189.

[23] P. Anielski. Hair analysis of anabolic steroids in connection with doping control-results from horse samples. J. Mass Spectrom. 2008, 43, 1001.

[24] G.L. Henderson. Mechanisms of drug incorporation into hair. Forensic Sci. Int. 1993, 63, 19.

[25] S. Balabanova, H.U. Wolf. Methadone concentrations in human hair of the head, axillary and pubic hair. Zeitschrift für Rechtsmedizin. 1989, 102, 293.

[26] P. Mangin, P. Kintz. Variability of opiates concentrations in human hair according to their anatomical origin: head, axillary and pubic regions. Forensic Sci. Int. 1993, 63, 77.

[27] M. Dunnett, P. Lees. Trace element, toxin and drug elimination in hair with particular reference to the horse. Res. Vet. Sci. 2003, 75, 89. 
[28] L. Rambaud, E. Bichon, N. Cesbron, F. André, B.L. Bizec. Study of 17ß-estradiol-3benzoate, $17 \alpha$-methyltestosterone and medroxyprogesterone acetate fixation in bovine hair. Anal. Chim. Acta. 2005, 532, 165.

[29] E. Duffy, M.H. Mooney, C.T. Elliott, M. O'Keeffe. Studies on the persistence of estradiol benzoate and nortestosterone decanoate in hair of cattle following treatment with growth promoters, determined by ultra-high-performance liquid chromatography-tandem mass spectrometry. J. Chromatogr. A. 2009, 1216, 8090.

[30] T. Müntener, M.G. Doherr, F. Guscetti, M.M. Suter, M.M. Welle. The canine hair cycle - a guide for the assessment of morphological and immunohistochemical criteria. Veterinary Dermatology. 2011, 22, 383.

[31] P.X. Min Shen, Hui Yan, Baohua Shen, Mengye Wang. Analysis of anabolic steroids in hair: Time course in guineal pigs. Steroids. 2009, 74,

[32] W.A.B.V.A.H.W.H. Blahd. Hair analysis for drugs of abuse. J. Forensic Sci. 1989, 34, 1433.

[33] C. Jurado, P. Kintz, M. Menéndez, M. Repetto. Influence of the cosmetic treatment of hair on drug testing. Int. J. Leg. Med. 1997, 110, 159.

[34] J. Röhrich, S. Zörntlein, L. Pötsch, G. Skopp, J. Becker. Effect of the shampoo Ultra Clean on drug concentrations in human hair. Int. J. Leg. Med. 2000, 113, 102.

[35] T. Cairns, V. Hill, M. Schaffer, W. Thistle. Removing and identifying drug contamination in the analysis of human hair. Forensic Sci. Int. 2004, 145, 97.

[36] V. Cirimele, P. Kintz, P. Mangin. Drug concentrations in human hair after bleaching. Journal of Analytical Toxicology. 1995, 19, 331.

[37] D.L. Blank, D.A. Kidwell. Decontamination procedures for drugs of abuse in hair: are they sufficient? Forensic Sci. Int. 1995, 70, 13.

[38] F. Pragst, M.A. Balikova. State of the art in hair analysis for detection of drug and alcohol abuse. Clin. Chim. Acta. 2006, 370, 17.

[39] P. Anielski, D. Thieme, A. Schlupp, J. Grosse, F. Ellendorff, R. Mueller. Detection of testosterone, nandrolone and precursors in horse hair. Analytical \& Bioanalytical Chemistry. 2005, 383, 903.

This article is protected by copyright. All rights reserved. 
Table 1 Parameters for High resolution accurate mass spectrometry analysis of testosterone esters in hair

\begin{tabular}{|c|c|c|c|c|}
\hline Analyte & $\begin{array}{l}\text { Precursor ion } \\
(\mathrm{m} / \mathrm{z})\end{array}$ & $\begin{array}{l}\text { Daughter ions used } \\
(\mathrm{m} / \mathrm{z})\end{array}$ & $\begin{array}{l}\text { High energy } \\
\text { collisional } \\
\text { dissociation } \\
\text { (\% Normalised } \\
\text { Collision } \\
\text { Energy) }\end{array}$ & $\begin{array}{l}\text { Retention } \\
\text { time (min) }\end{array}$ \\
\hline $\begin{array}{l}\text { Testosterone } \\
\text { propionate }\end{array}$ & 374.3 & $126.0913,138.0913$ & 50 & 3.75 \\
\hline $\begin{array}{l}\text { Testosterone phenyl } \\
\text { propionate }\end{array}$ & 450.3 & $\begin{array}{l}\text { 105.0702,126.0913, } \\
138.0913\end{array}$ & 50 & 5.1 \\
\hline $\begin{array}{l}\text { Testosterone } \\
\text { isocaproate }\end{array}$ & 416.3 & $126.0913,138.0913$ & 50 & 6.0 \\
\hline $\begin{array}{l}\text { Testosterone } \\
\text { enanthate }\end{array}$ & 430.3 & $126.0913,138.0913$ & 50 & 6.89 \\
\hline $\begin{array}{l}\text { Testosterone } \\
\text { decanoate }\end{array}$ & 472.4 & $126.0913,138.0913$ & 50 & 9.25 \\
\hline $\begin{array}{l}\text { Testosterone } \\
\text { Propionate d3 }\end{array}$ & 477.3 & $126.0913,138.0913$ & 50 & 3.73 \\
\hline $\begin{array}{l}\text { Testosterone } \\
\text { Enanthate d3 }\end{array}$ & 433.3 & $126.0913,138.0913$ & 50 & 6.87 \\
\hline $\begin{array}{l}\text { Testosterone } \\
\text { Decanoate d3 }\end{array}$ & 475.4 & $126.0913,138.0913$ & 50 & 9.23 \\
\hline
\end{tabular}

This article is protected by copyright. All rights reserved. 
Table 2 Validation parameters for the detection of testosterone esters in hair

\begin{tabular}{|c|c|c|c|c|c|c|c|c|}
\hline Analyte & $\begin{array}{l}\text { Linear } \\
\text { range } \\
(\mu \mathrm{g} / \mathrm{kg})\end{array}$ & $\begin{array}{l}\text { LOD } \\
(\mu \mathrm{g} / \mathrm{kg})\end{array}$ & $\begin{array}{l}\text { LOQ } \\
(\mu \mathrm{g} / \mathrm{kg})\end{array}$ & Recovery (\%) & $\begin{array}{l}\text { Inter-day } \\
\text { accuracy (\%) }\end{array}$ & $\begin{array}{l}\text { Inter-day } \\
\text { precision } \\
\text { (CV\%) }\end{array}$ & $\begin{array}{l}\text { Intra-day } \\
\text { accuracy }\end{array}$ & $\begin{array}{l}\text { Intra-day } \\
\text { precision } \\
\text { (CV\%) }\end{array}$ \\
\hline $\begin{array}{l}\text { Testosterone } \\
\text { propionate }\end{array}$ & 0.1-10 & 0.025 & 0.1 & 74 & 100.3 & 3.3 & 101.91 & 3.75 \\
\hline $\begin{array}{l}\text { Testosterone phenyl } \\
\text { propionate }\end{array}$ & $0.1-10$ & 0.05 & 0.1 & 70 & 99.6 & 8 & 101.45 & 9.56 \\
\hline $\begin{array}{l}\text { Testosterone } \\
\text { isocaproate }\end{array}$ & $0.1-10$ & 0.05 & 0.1 & 75 & 104.2 & 9.1 & 94.59 & 4.73 \\
\hline $\begin{array}{l}\text { Testosterone } \\
\text { enanthate }\end{array}$ & $0.25-10$ & 0.25 & 0.25 & 76 & 96.7 & 3.5 & 96.97 & 1.86 \\
\hline Testosterone & $0.1-10$ & 0.05 & 0.1 & 70 & 102.9 & 2 & 102.57 & 1.47 \\
\hline
\end{tabular}


Table 3 Concentration of testosterone esters $(\mu \mathrm{g} / \mathrm{kg})$ in right chest hair from dogs before drug administration $(\mathrm{n}=5) . \mathrm{LOQ}=0.1 \mu \mathrm{g} / \mathrm{kg}$ and $\mathrm{LOD}=0.05 \mu \mathrm{g} / \mathrm{kg}$ for all the testosterone esters, except testosterone propionate $(0.025 \mu \mathrm{g} / \mathrm{kg})$

\begin{tabular}{ccccc}
\hline Dog ID & T. Propionate & $\begin{array}{c}\text { T. Phenyl } \\
\text { propionate }\end{array}$ & T. Isocaproate & T. Decanoate \\
\hline 1 & 0.31 & 0 & 0.05 & 0 \\
2 & 0 & 0 & 0 & 0 \\
3 & 0 & 0 & 0 & 0 \\
4 & 0 & 0 & 0 & 0 \\
5 & 0 & 0 & 0 & 0 \\
6 & Removed from study & & & 0 \\
Control hair & 0 & 0 & $0.02<$ LOD & \\
\end{tabular}

This article is protected by copyright. All rights reserved. 
Table 4 Non compartmental data analysis of right chest hair $(n=5)$ using Phoenix WinNonlin software

\begin{tabular}{|c|c|c|c|c|c|c|}
\hline & Parameter & Units & T.propionate & $\begin{array}{l}\text { T.phenyl } \\
\text { propionate }\end{array}$ & T. isocaproate & T.decanoate \\
\hline \multirow[t]{3}{*}{ Dog1 } & $\mathrm{T} 1 / 2$ & Day & 11 & 15 & 11 & 11 \\
\hline & $\mathrm{T}_{\max }$ & Day & 2 & 2 & 2 & 2 \\
\hline & $\mathrm{C}_{\max }$ & $\mu \mathrm{g} / \mathrm{kg}$ & 2.57 & 6.54 & 5.47 & 5.80 \\
\hline \multirow[t]{3}{*}{ Dog2 } & $\mathrm{T} 1 / 2$ & Day & 7 & 7 & 5 & 5 \\
\hline & $\mathrm{T}_{\max }$ & Day & 4 & 2 & 2 & 2 \\
\hline & $C_{\max }$ & $\mu \mathrm{g} / \mathrm{kg}$ & 3.29 & 15.36 & 11.19 & 12.89 \\
\hline \multirow[t]{3}{*}{ Dog 3} & $\mathrm{~T} 1 / 2$ & Day & 6 & 20 & 18 & 6 \\
\hline & $\mathrm{T}_{\max }$ & Day & 2 & 2 & 2 & 2 \\
\hline & $\mathrm{C}_{\max }$ & $\mu \mathrm{g} / \mathrm{kg}$ & 2.63 & 11.60 & 10.30 & 11.18 \\
\hline \multirow[t]{3}{*}{ Dog4 } & $\mathrm{T} 1 / 2$ & Day & & 6 & 16 & 9 \\
\hline & $\mathrm{T}_{\max }$ & Day & 8 & 2 & 2 & 2 \\
\hline & $C_{\max }$ & $\mu \mathrm{g} / \mathrm{kg}$ & 1.13 & 3.99 & 3.39 & 4.29 \\
\hline \multirow[t]{3}{*}{ Dog 5} & $\mathrm{~T} 1 / 2$ & Day & & 6 & 5 & 5 \\
\hline & $\mathrm{T}_{\max }$ & Day & 4 & 2 & 2 & 2 \\
\hline & $\mathrm{C}_{\max }$ & $\mu \mathrm{g} / \mathrm{kg}$ & 2.88 & 6.28 & 5.09 & 8.10 \\
\hline
\end{tabular}

This article is protected by copyright. All rights reserved. 
Table 5 Total number of dogs in which the analytes were quantified and detected in tail hair $(n=5)$

\begin{tabular}{llllllllll}
\hline Analytes & \multicolumn{1}{c}{ Days } \\
& 77 & & 91 & 98 & & 100 & \\
& $>$ LOQ & $>$ LOD & $>$ LOQ & $>$ LOD & $>$ LOQ & $>$ LOD & $>$ LOQ & $>$ LOD \\
T. Propionate & 3 & 4 & 3 & 3 & 3 & 5 & 4 & 4 \\
T. Phenyl propionate & 3 & 4 & 2 & 3 & 5 & 5 & 5 & 5 \\
T. Isocaproate & 2 & 2 & 2 & 2 & 4 & 5 & 4 & 4 \\
T. Decanoate & 2 & 2 & 3 & 3 & 2 & 5 & 2 & 3 \\
\hline
\end{tabular}

This article is protected by copyright. All rights reserved. 
Table 6 Concentration $(\mu \mathrm{g} / \mathrm{kg})$ of testosterone esters above limit of detection in hair of right chest of each dog from 35 to 91 days post administration of Sustanon ' 250 '

\begin{tabular}{cccccc}
\hline Dog ID & Time (Days) & $\begin{array}{c}\text { Testosterone } \\
\text { propionate }\end{array}$ & $\begin{array}{c}\text { Testosterone } \\
\text { phenyl } \\
\text { propionate }\end{array}$ & $\begin{array}{c}\text { Testosterone } \\
\text { isocaproate }\end{array}$ & $\begin{array}{c}\text { Testosterone } \\
\text { decanoate }\end{array}$ \\
\hline 1 & 35 & 0.26 & 0.38 & 0.28 & 0.41 \\
2 & 35 & 0.04 & 0.15 & 0.06 & 0 \\
3 & 35 & 0.08 & 0.34 & 0.16 & 0.18 \\
4 & 35 & 0 & 0.10 & 0.60 & 0.07 \\
5 & 35 & 0 & 0 & 0 & 0 \\
1 & 63 & 0.09 & 0.11 & 0.06 & 0.07 \\
2 & 63 & 0 & 0.07 & 0 & 0 \\
3 & 63 & 0 & 0.05 & 0 & 0 \\
4 & 63 & 0 & 0.05 & 0 & 0 \\
5 & 63 & 0 & 0 & 0 & 0 \\
1 & 77 & 0.09 & 0 & 0 & 0 \\
2 & 77 & 0.00 & 0 & 0 & 0 \\
3 & 77 & 0 & 0.34 & 0.19 & 0 \\
4 & 77 & 0 & 0 & 0 & 0 \\
5 & 77 & 0.03 & 0 & 0 & 0 \\
1 & 91 & 0 & 0 & 0 & 0 \\
2 & 91 & 0.08 & 0 & 0 & 0 \\
3 & 91 & 0 & 0 & 0 & 0 \\
4 & 91 & 0 & 0 & 0 & 0 \\
5 & 91 & 0.06 & 0 & 0 & 0 \\
\hline
\end{tabular}

This article is protected by copyright. All rights reserved. 
Table 7 Detection time window of the testosterone esters in hair of right chest in each dog. TP-testosterone propionate, TPP-testosterone phenyl propionate, TI-testosterone isocaproate, TD-testosterone decanoate

\begin{tabular}{llllll}
\hline Dog ID & $\begin{array}{l}\text { T. } \\
\text { propionate }\end{array}$ & $\begin{array}{l}\text { T. phenyl } \\
\text { propionate }\end{array}$ & $\begin{array}{l}\text { T. } \\
\text { Isocaproate }\end{array}$ & T.decanoate & Order of detection \\
\hline & Days & Days & Days & Days & \\
$\mathbf{1}$ & 77 & 63 & 63 & 63 & TPP $=\mathrm{Tl}=\mathrm{TD}<\mathrm{TP}$ \\
$\mathbf{2}$ & 91 & 63 & 35 & 21 & $\mathrm{TD}<\mathrm{Tl}<\mathrm{TPP}<\mathrm{TP}$ \\
$\mathbf{3}$ & 35 & 77 & 77 & 35 & $\mathrm{TP}=\mathrm{TD}<\mathrm{TPP}=\mathrm{TI}$ \\
$\mathbf{4}$ & 21 & 63 & 35 & 35 & $\mathrm{TP}<\mathrm{Tl}=\mathrm{TD}<\mathrm{TPP}$ \\
$\mathbf{5}$ & 91 & 21 & 21 & 21 & $\mathrm{TPP}=\mathrm{Tl}=\mathrm{TD}<\mathrm{TP}$ \\
\hline
\end{tabular}

This article is protected by copyright. All rights reserved. 
Table 8 Estimated concentration $(\mu \mathrm{g} / \mathrm{kg})$ of testosterone esters in the chest hair from five dogs at 63 and 77 days, which were subjected to washing and no washing with shampoo

\begin{tabular}{|c|c|c|c|c|c|c|c|c|c|}
\hline \multirow[t]{2}{*}{ Dog ID } & \multirow[t]{2}{*}{ Day } & \multicolumn{2}{|c|}{ T. propionate } & \multicolumn{2}{|c|}{$\begin{array}{l}\text { T.phenyl } \\
\text { propionate }\end{array}$} & \multicolumn{2}{|c|}{ T. isocaproate } & \multicolumn{2}{|c|}{ T.decanoate } \\
\hline & & Unwash & Wash & Unwash & Wash & Unwash & Wash & Unwash & Wash \\
\hline 1 & 63 & 0.09 & 0.18 & 0.11 & 0.23 & 0.06 & 0.15 & 0.07 & 0.00 \\
\hline 2 & 63 & 0.00 & 0.05 & 0.07 & 0.12 & 0.00 & 0.00 & 0.00 & 0.00 \\
\hline 3 & 63 & 0.00 & 0.07 & 0.05 & 0.08 & 0.00 & 0.00 & 0.00 & 0.00 \\
\hline 4 & 63 & 0.00 & 0.06 & 0.05 & 0.13 & 0.00 & 0.00 & 0.00 & 0.00 \\
\hline 5 & 63 & 0.00 & 0.14 & 0.00 & 0.05 & 0.00 & 0.00 & 0.00 & 0.00 \\
\hline 1 & 77 & 0.09 & 0.11 & 0.00 & 0.00 & 0.00 & 0.00 & 0.00 & 0.00 \\
\hline 2 & 77 & 0.00 & 0.04 & 0.00 & 0.00 & 0.00 & 0.00 & 0.00 & 0.00 \\
\hline 3 & 77 & 0.00 & 0.04 & 0.34 & 0.00 & 0.19 & 0.00 & 0.00 & 0.00 \\
\hline 4 & 77 & 0.00 & 0.04 & 0.00 & 0.00 & 0.00 & 0.00 & 0.00 & 0.00 \\
\hline 5 & 77 & 0.03 & 0.03 & 0.00 & 0.00 & 0.00 & 0.00 & 0.00 & 0.00 \\
\hline
\end{tabular}

This article is protected by copyright. All rights reserved. 
Table 9 Mean concentration of testosterone esters in decontamination washes of tail hair in 100 days post administration of Sustanon '250' in three dogs. Units are $\mu \mathrm{g} / \mathrm{L}$ (washes) and $\mu \mathrm{g} / \mathrm{kg}$ (hair)

\begin{tabular}{lllll}
\hline Analytes & & Dog 1 & Dog3 & Dog5 \\
\hline T.propionate & Wash1 & 1.44 & 1.31 & 0.19 \\
& Wash2 & 0.16 & 0.14 & 0.05 \\
& Wash3 & 0.14 & 0.04 & 0.02 \\
& Hair & 0.92 & 0.20 & 0.46 \\
T.phenyl & & & \\
propionate & Wash1 & 2.63 & 0.08 & 0.06 \\
& Wash2 & 0.06 & & \\
& Wash3 & 0.06 & 0.06 & 0.06 \\
& Hair & 0.63 & 0.06 & 0.06 \\
& & & 0.23 & \\
T.isocaproate & Wash1 & 2.53 & & 0.64 \\
& Wash2 & 0.33 & 0.86 & 0.28 \\
& Wash3 & 0.22 & 0.65 & 0.08 \\
& Hair & 0.59 & 0.34 & 0.04 \\
& & & 0.43 & \\
T.decanoate & Wash1 & 8.61 & & 0.83 \\
& Wash2 & 0.70 & 1.06 & 0.18 \\
& Wash3 & 0.43 & 0.14 & 0.11 \\
& Hair & 0.73 & 0.11 & 0.07 \\
\hline
\end{tabular}


Table 10 Concentration $(\mu \mathrm{g} / \mathrm{L})$ of testosterone and its metabolites in urine of pre drug administered dogs.

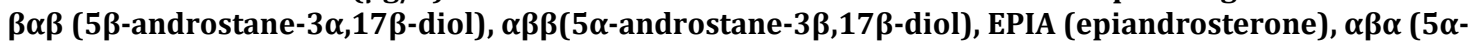
androstane-3 $\beta, 17 \alpha$-diol), TEST (testosterone), EPIT (epitestosterone), ETIO (etiocholanolone)

\begin{tabular}{lccccccc}
\hline Dog ID & $\beta \alpha \beta$ & $\alpha \beta \beta$ & EPIA & $\alpha \beta \alpha$ & TEST & EPIT & ETIO \\
\hline 1 & 5.27 & 3.74 & 5.41 & 4.44 & 0.26 & 0.23 & 1.23 \\
2 & 6.18 & 5.89 & 9.26 & 1.43 & 0.71 & 0.16 & 0.88 \\
3 & 3.05 & 3.90 & 2.88 & 1.83 & 0.04 & 0.01 & 1.36 \\
4 & 8.36 & 7.77 & 10.11 & 2.15 & 0.69 & 0.25 & 1.33 \\
& & & & & & & \\
5 & 4.09 & 7.91 & 12.04 & 2.48 & 1.24 & 0.10 & 1.14 \\
\hline
\end{tabular}

This article is protected by copyright. All rights reserved. 


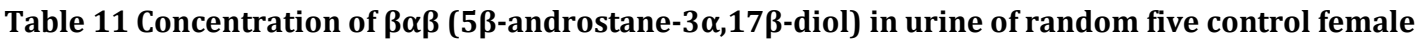
greyhound dogs (Data acquired from previous studies conducted at RASL Victoria, Australia, in collaboration with UNSW, Australia)

\begin{tabular}{ccc}
\hline Dog number & Concentration of $\beta \alpha \beta$ in control dogs $(\mu \mathrm{g} / \mathrm{L})$ \\
\hline 1 & 0.00 \\
2 & 0.27 \\
3 & 0.25 \\
4 & 0.44 \\
5 & 0 \\
\hline
\end{tabular}

This article is protected by copyright. All rights reserved. 
Table 12 Mean concentration $(\mu \mathrm{g} / \mathrm{L})$ of testosterone and its metabolites in pre and post drug administration urine samples in five dogs. $\beta \alpha \beta(5 \beta$-androstane-3 $\alpha, 17 \beta$ -

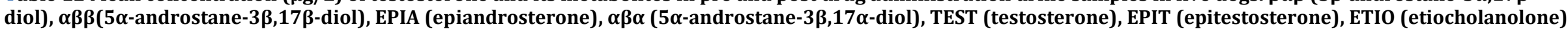

\begin{tabular}{|c|c|c|c|c|c|c|c|}
\hline Hours (Days) & $\beta \alpha \beta$ & $\alpha \beta \beta$ & $\alpha \beta \alpha$ & ETIO & EPIA & TEST & EPIT \\
\hline 0 & 5.39 & 5.84 & 2.47 & 1.19 & 7.94 & 0.59 & 0.15 \\
\hline 2 & 35.59 & 25.13 & 9.90 & 3.06 & 26.99 & 1.78 & 0.13 \\
\hline $48(2)$ & 41.91 & 33.94 & 11.59 & 6.77 & 41.27 & 1.63 & 0.20 \\
\hline $96(4)$ & 17.08 & 17.93 & 6.03 & 2.42 & 19.17 & 0.44 & 0.48 \\
\hline $192(8)$ & 5.77 & 5.37 & 1.83 & 1.05 & 5.71 & 0.16 & 0.13 \\
\hline $360(15)$ & 11.09 & 11.73 & 3.34 & 0.72 & 10.14 & 0.82 & 0.51 \\
\hline $504(21)$ & 10.62 & 9.96 & 3.76 & 2.03 & 9.69 & 0.33 & 0.18 \\
\hline $672(28)$ & 14.70 & 17.44 & 4.90 & 1.15 & 16.45 & 1.04 & 0.35 \\
\hline $840(35)$ & 9.55 & 19.11 & 5.42 & 0.94 & 18.00 & 0.47 & 0.60 \\
\hline 1176 (49) & 7.38 & 9.02 & 2.54 & 0.82 & 8.96 & 0.54 & 0.31 \\
\hline $1512(63)$ & 6.76 & 8.01 & 2.58 & 1.03 & 6.89 & 0.42 & 0.24 \\
\hline $1848(77)$ & 17.19 & 16.86 & 5.95 & 2.20 & 17.36 & 0.71 & 0.18 \\
\hline 2184 (91) & 18.51 & 12.65 & 5.11 & 0.82 & 13.99 & 0.60 & 0.26 \\
\hline
\end{tabular}




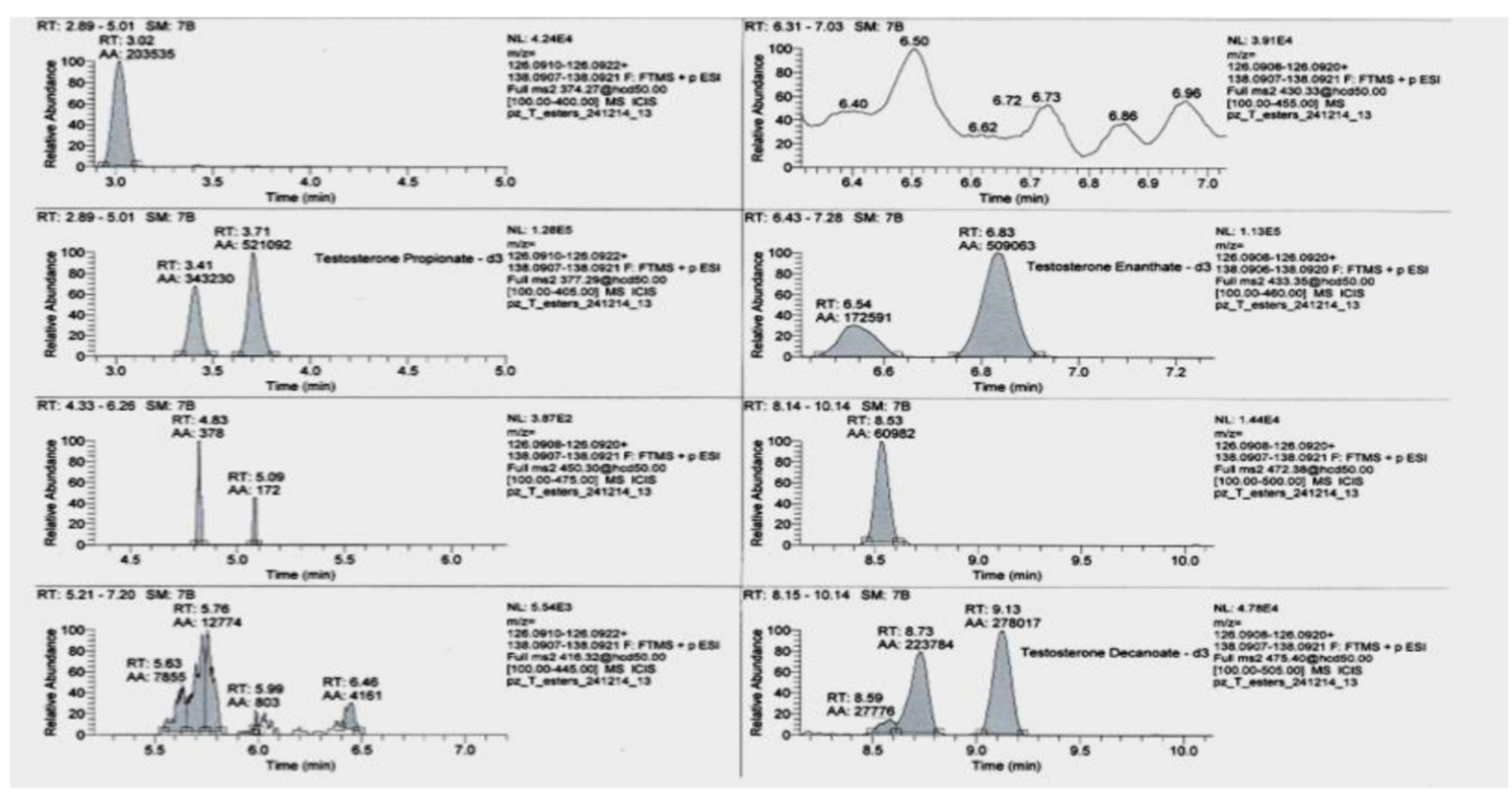

Figure 1 HRAM product ion chromatogram of control hair containing d3 internal standards but not the standard testosterone esters

DTA_2236_F1.TIF

This article is protected by copyright. All rights reserved. 


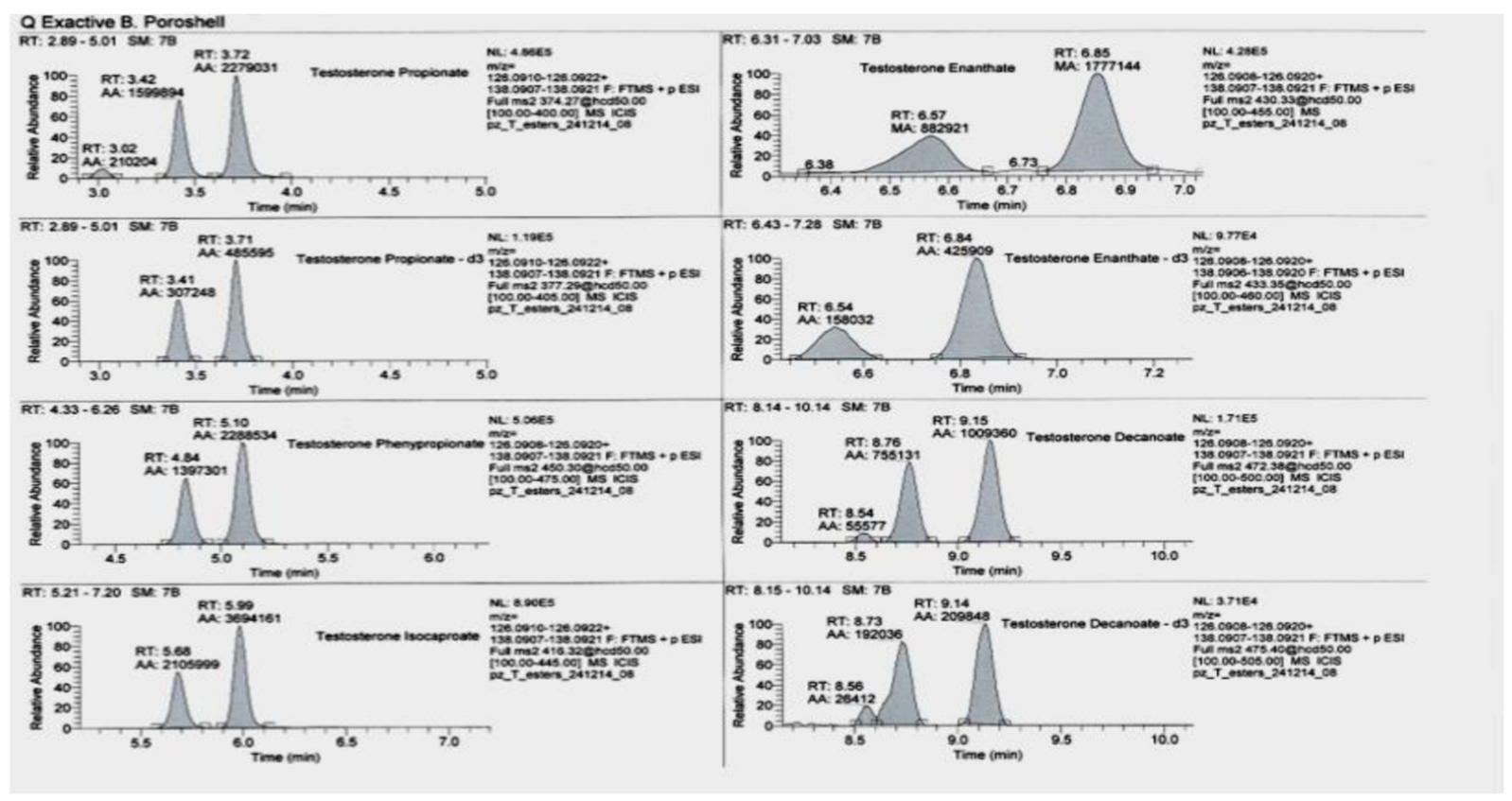

Figure 2 Extracted HRAM ion chromatogram obtained from hair samples spiked with $5 \mu \mathrm{g} / \mathrm{kg}$ each of testosterone esters showing both the deuterated internal standards and testosterone esters

DTA_2236_F2.TIF

This article is protected by copyright. All rights reserved. 


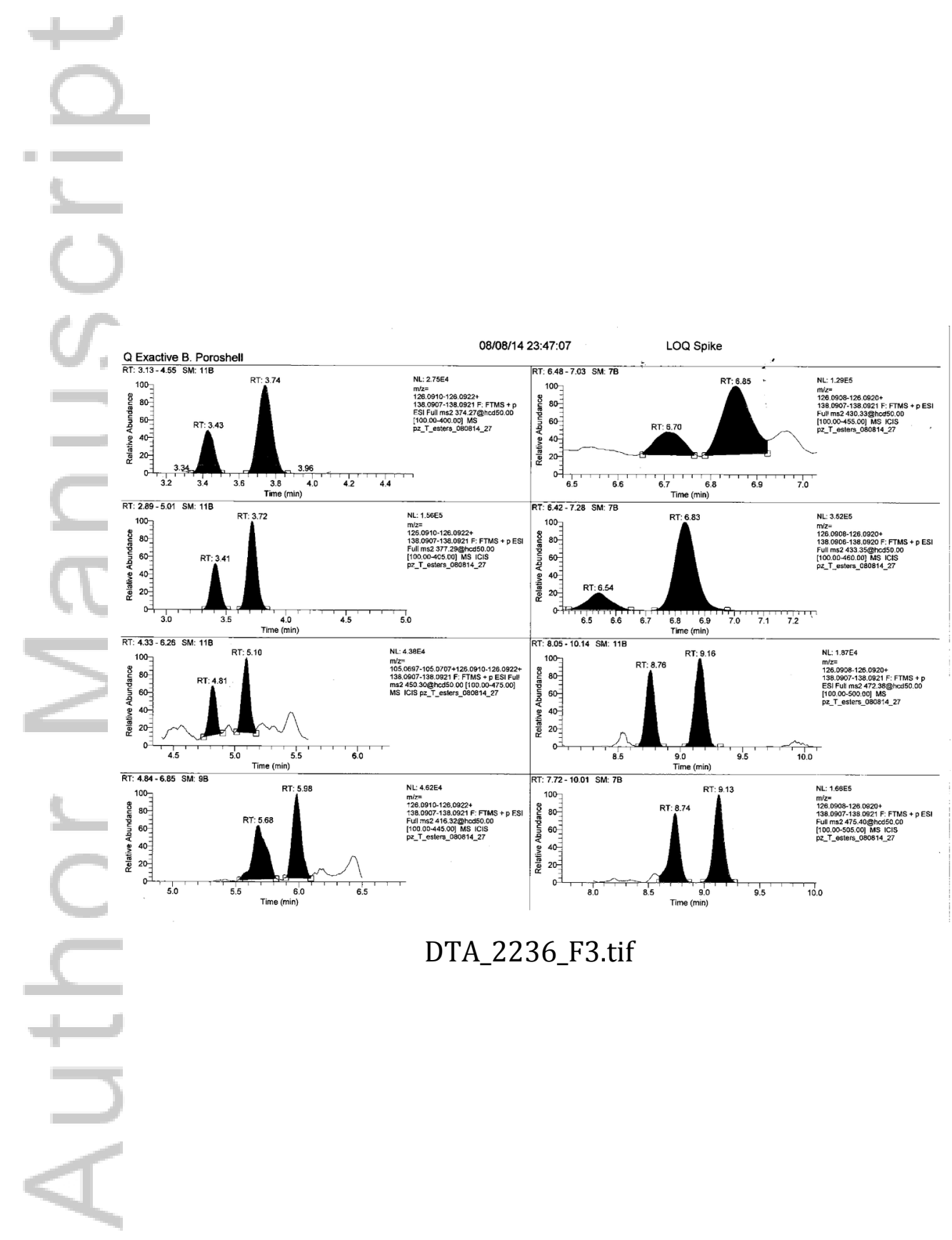

This article is protected by copyright. All rights reserved. 


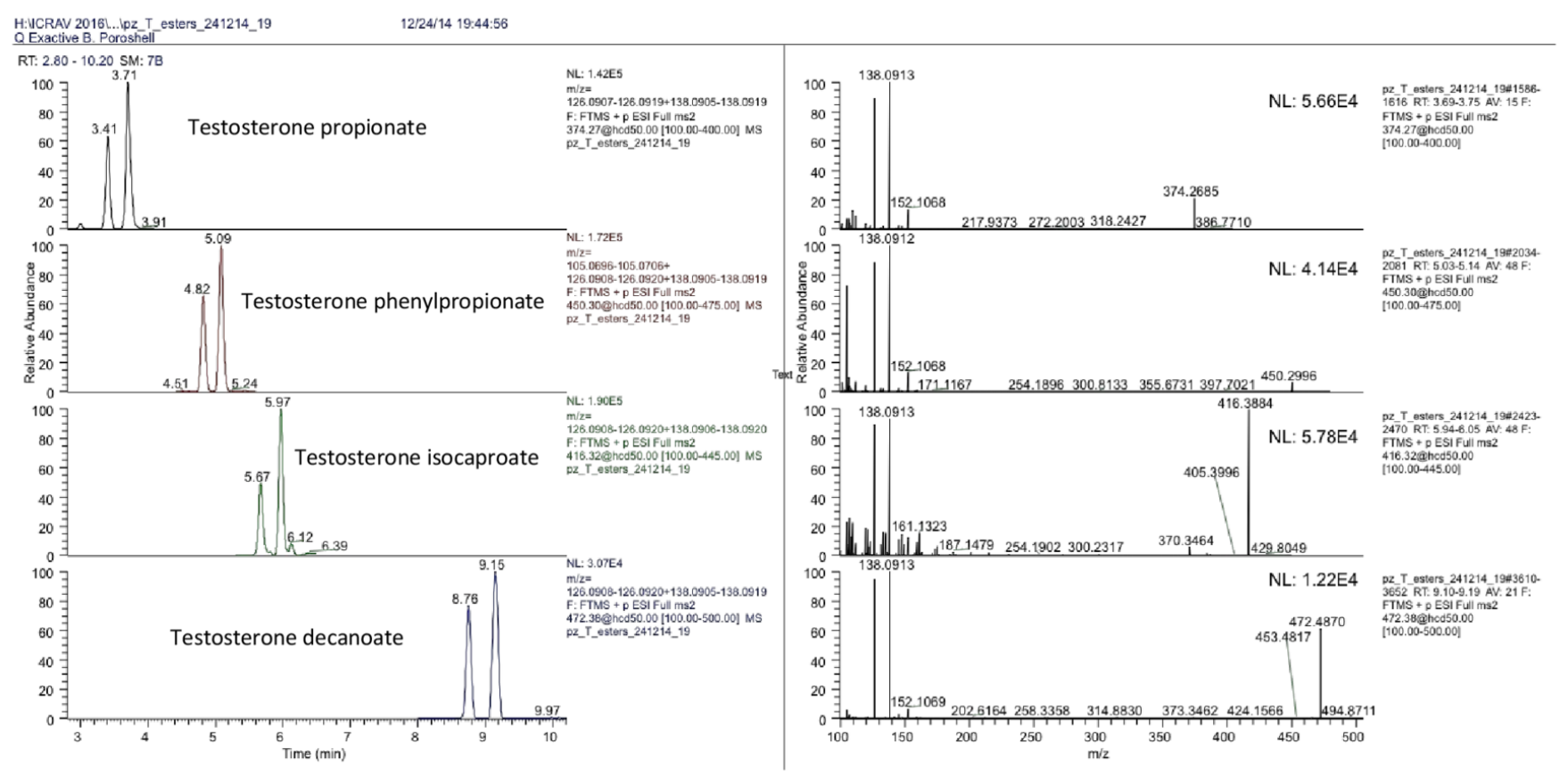

Figure 3 Chromatogram showing the detection of testosterone esters in tail hair of a dog in 98 days after drug administration.

DTA_2236_F4.TIF

This article is protected by copyright. All rights reserved. 
a)

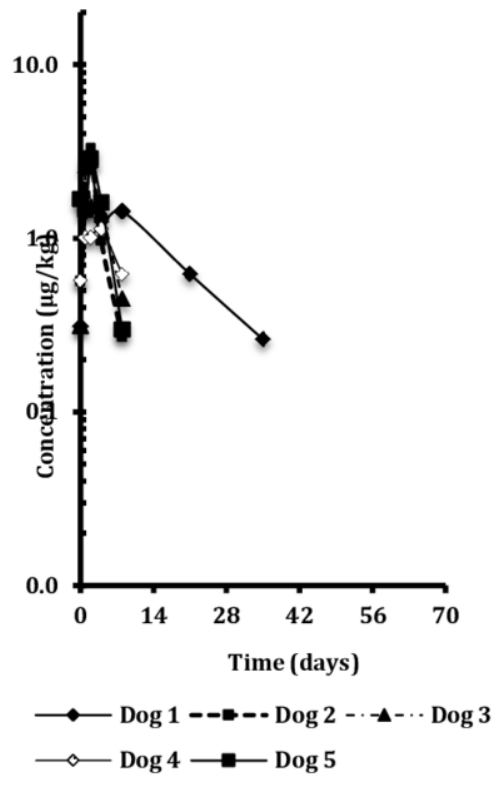

c)

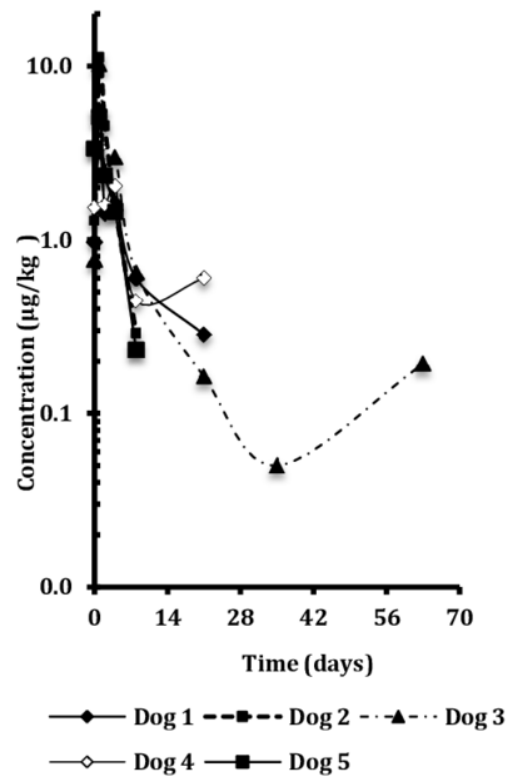

b)

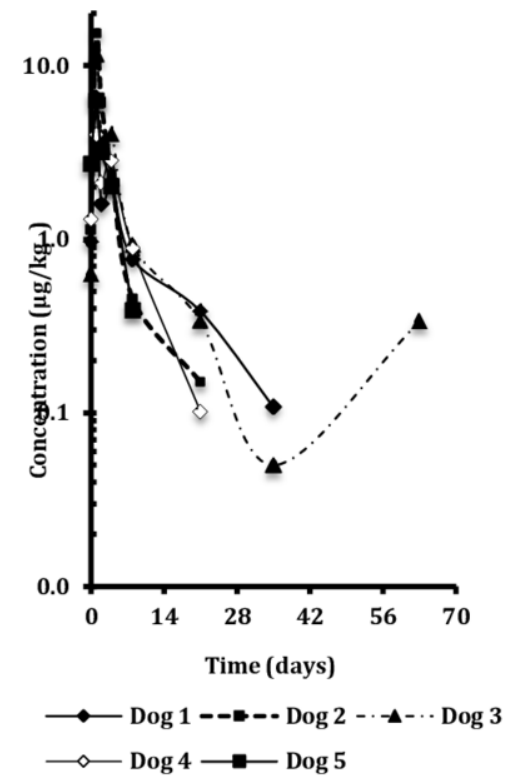

d)

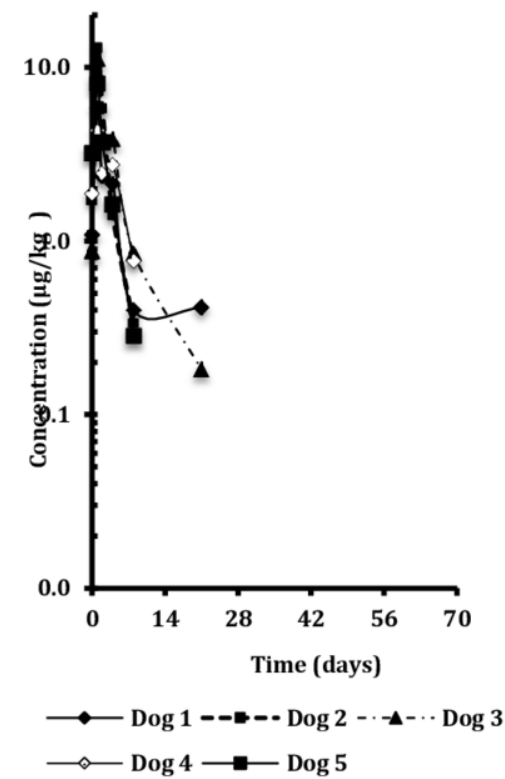

Figure 4 Concentration versus time curve of a) testosterone propionate b) testosterone phenyl propionate c) testosterone isocaproate and d) testosterone decanoate in five dogs in the hair of right chest 


\section{Determination of testosterone esters in the hair of male greyhound dogs using liquid chromatography high resolution mass spectrometry}

Jayasree Leela Devi*, Paul Zahra, John H. Vine, Ted Whittem
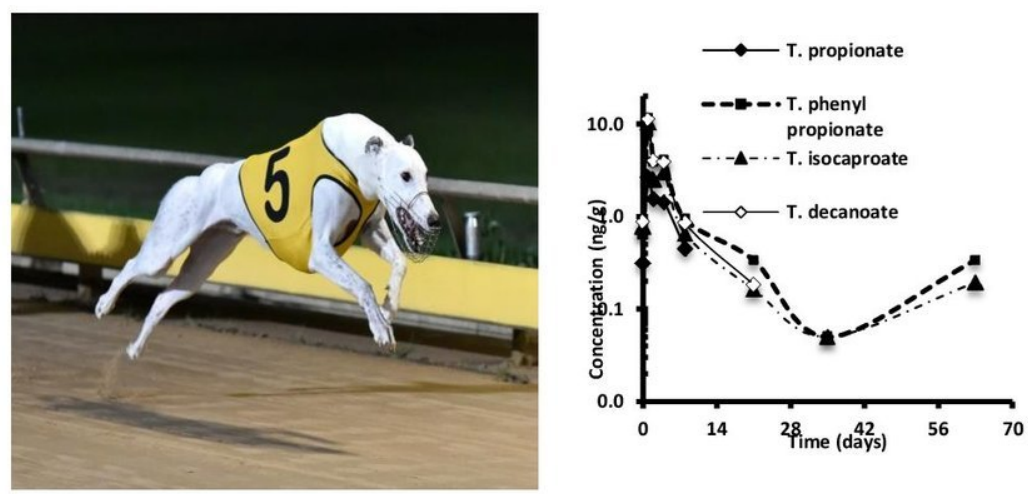

The study demonstrates that the use of a liquid chromatography-high resolution mass spectrometry method with heated electrospray ionisation (HESI) combined with the use of amino SPE cartridges for sample clean up, improves the selectivity and sensitivity of the method for the determination of propionate, phenyl propionate, isocaproate, decanoate and enanthate esters of testosterone in greyhound hair. This method was applied to hair samples collected from male greyhounds before and after a single administration of a product containing several testosterone esters each of which could be detected up to 100 days post-administration. 


\section{University Library}

\section{- M M N E R VA A gateway to Melbourne's research publications}

Minerva Access is the Institutional Repository of The University of Melbourne

Author/s:

Devi, JL;Zahra, P;Vine, JH;Whittem, T

Title:

Determination of testosterone esters in the hair of male greyhound dogs using liquid chromatography-high resolution mass spectrometry

Date:

2018-03-01

\section{Citation:}

Devi, J. L., Zahra, P., Vine, J. H. \& Whittem, T. (2018). Determination of testosterone esters in the hair of male greyhound dogs using liquid chromatography-high resolution mass spectrometry. DRUG TESTING AND ANALYSIS, 10 (3), pp.460-473. https://doi.org/10.1002/ dta.2236.

Persistent Link:

http://hdl.handle.net/11343/293360 